\title{
Integrating Individual Strategies in the Job Demands-Resources Theory
}

\section{Evangelia Demerouti ${ }^{1}$}

\begin{abstract}
The Job Demands-Resources (JD-R) model was introduced in the 00's to explain the causes of burnout. Later it matured into JD-R theory that can explain how various employee and organizational outcomes develop. Job demands are responsible for the health impairment process, whereas job resources initiate a motivational process. These processes occur simultaneously and have unique as well as interactive effects on outcomes. The role of the individual in the form of personal resources was added in the JD-R theory more recently. The current paper expands the role of the individual in the JD-R theory even further by presenting strategies that individuals use to (i) deal directly with the unfavorable effects of job characteristics including actual or anticipated loss of resources, namely coping and recovery; (ii) maximize favorable effects, goal achievement and avoid losses, i.e., self-regulation and (iii) alter job characteristics such that they are less demanding and more motivating, i.e., job crafting. It is discussed that individual strategies can be integrated in the JD-R Theory, both as a mediator and a moderator of both processes. It is my hope that JD-R Theory will continue to inspire researchers and practitioners who want to promote employee well-being and effective organizational functioning.
\end{abstract}

\section{Keywords}

Burnout • Coping • Job crafting • Job demands-resources theory $\bullet$ Recovery $\bullet$ Self-regulation

The Job Demands-Resources (JD-R) Model is a theoretical model introduced by Demerouti, Bakker, Nachreiner, and Schaufeli in 2001. In their seminal paper, Demerouti and colleagues identified 21 so-called job demands and job resources as potential causes of burnout. They drew upon a broad conceptualization of burnout, which is reflected in the Oldenburg Burnout Inventory that differentiates be- tween exhaustion and disengagement from work as dimensions of burnout that can occur in virtually every job. In the meantime, the model has grown to a complete Job Demands-Resources (JD-R) Theory. Almost immediately after its introduction, the JD-R Theory gained popularity with many empirical studies applying the model to various occupational groups. One likely reason for this popularity is that, in line with the Demand Control Support Model (Karasek \& Theorell, 1990) and Effort-Re-

\footnotetext{
1 Corresponding author: Evangelia Demerouti (Prof.), Technische Universiteit Eindhoven, Industrial Engineering \& Innovation Sciences, Netherlands. Email: e.demerouti@tue.nl

To cite this article: Demerouti, E. (2018), Integrating individual strategies in the job demands-resources theory. Istanbul Business Research, 47(1), 7-34. http://dx.doi.org/10.26650/ibr.2018.47.1.0001
} 
ward-Imbalance Model (Siegrist, 1996), the JD-R Model assumes that employee adverse health and poor motivation result from a lack of balance between (high) job demands and (low) job resources. However, unlike those two models, the JD-R Model does not restrict itself to a single job demand and a single job resource. The model assumes that any job demand and any job resource may affect employee health and motivation, as long as these demands and resources are a salient or relevant aspect of a particular job. Moreover, and in contrast to these models, the JD-R Theory focusses simultaneously on the stress and the motivational processes that take place at work due to specific work characteristics, the job demands and job resources, respectively. In this way, the JD-R Theory parsimoniously explains the main processes at work explaining the well-being and the resulting behavior of employees. As will be explained later, ideally the application of the JD-R Theory in a specific job starts with an inventarisation of the prevailing demands and resources for that specific job (through interviews with job holders and/or supervisors). Thus, the scope of the JD-R Theory is much broader than that of the two other models, because it potentially includes all job demands and all job resources that can prevail in a particular job. The JD-R Theory is therefore more flexible and can be tailored to a much wider variety of work settings. The broader scope of the model as well as its simplicity appeals to researchers, just as its flexibility is attractive to practitioners (Schaufeli \& Taris, 2014).
Being a work psychological theory, the JD-R Theory emphasizes the importance of job characteristics. Although there is no doubt that the presence of demanding job characteristics combined with the absence of resources or motivational job characteristics are important for employee burnout or well-being in general, it is interesting from both a theoretical and practical point of view to examine whether there are strategies that individuals use to alter the impact of job characteristics so that the unfavorable effects are minimized whereas the favorable ones are maximized. Individual strategies represent methods or plans that people choose to achieve a goal or solve a problem, which generally involve some planning or marshaling of resources for their most efficient and effective use (Demerouti, 2015). Insight into individual strategies may uncover what individuals do to alter job characteristics or the impact of job characteristics on their own well-being. Such strategies can be effective or non-effective and their effectiveness may depend on the situations in which the strategies are used. Finding such bottom-up strategies that help individuals to minimize unfavorable and maximize favorable effects of job characteristics may be essential to complement the top-down interventions that organizations introduce to improve well-being and functioning at work (Demerouti, 2015). Specifically, insight into individual strategies can help the development of interventions targeted to guide individuals such that they apply strategies that are more effective and refrain from using non-effective strategies. 
The current paper will focus on three categories of strategies that are suggested to be relevant to the JD-R Theory. First, strategies that individuals use to deal directly with the unfavorable effects of job characteristics which may be actual or anticipated loss of resources. Some target the individual's relationship to the job (i.e., coping), while others focus on strengthening the individual's internal resources (i.e., recovery) (Maslach \& Goldberg, 1998). A second category represents strategies that individuals use to maximize favorable effects, achieve their goals and avoid losses (i.e., self-regulation). Third, strategies that individuals apply to change their job characteristics directly such that the job is less demanding and more motivating (i.e., job crafting). The paper will end with a conclusion on how successful strategies may be stimulated among employees and some avenues will be suggested for future research related to the issue of individual strategies. After presenting the key assumptions of the JD-R Theory, an overview of empirical evidence as well as an evaluation of the theory, the role of the three categories of individual strategies in the JD-R Theory will be discussed.

\section{The Job Demands-Resources Theory}

\section{Key assumptions of the JD-R Theory}

The JD-R Theory departs from the premise that every occupation may have its own specific risk factors associated with job stress and impaired well-being and functioning. These factors can be classified in two general categories (i.e. job demands and job re- sources), constituting an overarching model that may be applied to various occupational settings, irrespective of the particular job demands and job resources involved (Bakker \& Demerouti, 2007). Within the JD-R Theory, job demands refer to those physical, psychological, social, or organizational aspects of the job that require sustained physical and/or psychological (cognitive and emotional) effort or skills and are therefore associated with certain physiological and/or psychological costs. Examples are a high work pressure, irregular working hours, an unfavorable physical environment, and emotionally demanding interactions with clients. Although job demands are not necessarily negative in nature, they may turn into so-called job stressors when meeting those demands requires too much effort.

Job resources within the JD-R Theory refer to those physical, psychological, social, or organizational aspects of the job that are either (1) functional in achieving work goals, (2) reducing job demands and the associated physiological and psychological costs, or (3) stimulating personal growth, learning, and development. Hence, job resources are not only necessary to deal with job demands, but they also are important in their own right. This complies with Hackman and Oldham's (1980) Job Characteristics Model, which emphasizes the motivational potential of job resources at the task level, including autonomy, feedback, and task significance. On a more general level, this agrees also with Hobfoll's (2002) Conservation of Resources (COR) theory, which states that the prime human 
motivation is directed towards the maintenance and accumulation of resources. Accordingly, resources are valued in their own right or because they are means to the achievement or protection of other valued resources. Resources may be located at the level of the organization at large (e.g., pay, career opportunities, job security), the interpersonal and social relations (e.g., supervisor and co-worker support, team climate), the organization of work (e.g., role clarity, participation in decision making), and at the level of the task (e.g., skill variety, task identity, task significance, autonomy, performance feedback). Although too high demands and lack of resources are both experienced as negative there are substantial differences in the reasons and the consequences of these negative experiences. High demands are experienced as negative because they consume energy and the outcome is health impairment and energy consumption. Lack of resources is also experienced as negative because their facilitating role is absent and the outcome is reduced motivation.

A second premise of the JD-R Theory is that two different underlying psychological processes play a role in the development of health and motivation (see Figure 1). In the first process, the so-called energetic or health impairment process, chronic job demands (e.g., work overload, emotional demands) exhaust employee's mental and physical resources and may therefore lead to the depletion of energy (i.e., a state of exhaustion, which represents the prime indicator of burnout) and to health prob- lems. Such a gradual draining of resources occurs because employees want to maintain their performance at work. When individuals are confronted with high job demands or environmental stressors (e.g., noise, heat, workload, time pressure), they use performance-protection strategies (Hockey, 1993). Performance protection is achieved through the mobilization of sympathetic activation (e.g., cardiovascular reactivity) and increased subjective effort (i.e., self-reports on having to mobilize many resources). Use of these strategies prevents overt decrements in primary task performance. Hockey (1993) called these attempts of people to sustain their performance standards 'resistance to degradation'. However, these strategies are not always effective. According to Hockey, several patterns of indirect degradation may be identified, such as risky choices and high subjective fatigue, and it is these patterns that ultimately lead to diminished job performance. The long-term effect of these strategies may be a draining of an individual's energy resources, but also deterioration of performance on specific task dimensions, such as task quality. So, energy depletion and health problems are assumed to (partly) mediate the relation between job demands and organizational outcomes.

The second process is motivational in nature, whereby it is assumed that job resources have motivational potential and lead to high work engagement, low cynicism, and consequently excellent job performance. Within the JD-R Theory, by definition, job resources may play an 
intrinsic motivational role because they foster employee's growth, learning and development. They also help to achieve work goals. Specifically, job resources fulfil basic human needs, such as a need for autonomy, competence, or relatedness. For instance, proper feedback fosters learning, thereby increasing job competence, whereas job discretion and social support satisfy the need for autonomy and the need to belong, respectively. Another example is that supportive colleagues and proper feedback from one's superior increases the likelihood of being successful in achieving one's work goals. To summarize, the presence of job resources leads to engagement, whereas their absence evokes a cynical attitude towards work. In turn, this affective-motivational state fosters positive organizational outcomes, such as organizational commitment and job performance. Thus, motivation and engagement are assumed to (partly) mediate the relation between job resources and organizational outcomes.

Job demands and resources initiate different processes, but they also have joint effects (reflected by the dotted lines in Figure 1). The third proposition put forward by the JD-R Theory is that job resources can buffer the impact of job demands in predicting employee health and motivation. Typically, the buffer or interaction hypothesis explains interactions between job demands and job resources by proposing that the relation between job demands and adverse health will be weaker for those enjoying a high degree of job resources. The buffer hypothesis is consistent with Kahn and By- osiere (1992), who argue that the buffering or interaction effect could occur between any pair of variables in the stress-strain sequence. They claim that properties of the work situation, as well as characteristics of the individual, can buffer the effects of a demand. The buffering effect of resources can take different forms: (1) they reduce the tendency of organizational properties to generate specific demands, (2) they alter the perceptions and cognitions evoked by such demands, (3) they moderate responses that follow the appraisal process, or (4) reduce the health-damaging consequences of such responses (Kahn \& Byosiere, 1992).

Which job demands and job resources play a role in a certain organisation or job function depends upon the tasks that need to be fulfilled and the conditions under which they are executed. In support of this suggestion, several studies have shown that job resources like social support, autonomy, performance feedback, and opportunities for development can mitigate the impact of job demands (such as work pressure, emotional demands, etc.) on job-related strain, including burnout (e.g., Bakker, Demerouti, \& Euwema, 2005; Xanthopoulou, Bakker, Demerouti, \& Schaufeli, 2007). Employees who have sufficient levels of job resources available can cope better with their daily job demands. This proposition is similar to the proposition of the DCS Model that job control and workplace social support can buffer the detrimental effects of job demands or to the proposition of the ERI model where occupational rewards can buffer the detrimental effects 
of efforts at work. Thus, the JD-R Theory states that different types of job demands and job resources may interact in predicting both health and motivation.

The fourth proposition of the JD-R Theory is that job resources particularly influence motivation or work engagement when job demands are high. This represents the so-called coping hypothesis (Bakker, Hakanen, Demerouti, \& Xanthopoulou, 2007). Coping can be defined as "constantly changing cognitive and behavioral efforts to manage specific demands that are appraised as taxing" (cf. Cummings, Greene, \& Karraker, 1991, p. 92). This hypothesis suggests that job resources become most salient under highly demanding conditions. In that case, employees will be more likely to use job resources as a coping mechanism. To conclude, there is a need for a challenge (i.e., job demand) for job resources as 'coping' to be translated into task enjoyment and work engagement.

As previously indicated, the JD-R Theory was initially developed as a work-psychological model, focusing on job demands and job resources only. An important extension and fifth proposition of the model is the inclusion of personal resources in the model. Personal resources are aspects of the self that are generally linked to resiliency and refer to individuals' sense of their ability to control and impact upon their environment successfully (Hobfoll, Johnson, Ennis, \& Jackson, 2003). Examples of personal resources that have been studied within the JD-R Theory are self-efficacy, optimism, and organizational-based self-esteem (Xanthopoulou, Bakker, Heuven, Demerouti, \& Schaufeli, 2008). The reason for this is that the higher an individual's personal resources, the more positive the person's self-regard and the more goal self-concordance is expected to be experienced (Judge, Bono, Erez, \& Locke, 2005). Individuals with goal self-concordance are intrinsically motivated to pursue their goals and as a result trigger higher performance and satisfaction. Personal resources might have two functions in the JD-R Theory: (1) to buffer the impact of job demands on health or energy-related outcomes and (2) to mediate the relation between job resources and motivational outcomes.

\section{Evidence for the JD-R Theory}

The JD-R Theory has been tested in various countries and cultures as well as in various occupational contexts (e.g., see overviews in Bakker \& Demerouti, 2007, 2014, 2017; Crawford, LePine, \& Rich, 2010; Demerouti \& Bakker, 2011). Generally, and in line with the assumptions of the theory, most empirical studies provide evidence that irrespective of cultural background and occupational uniqueness, the working conditions (i.e., job demands and job resources) evoke two distinct processes, namely (1) the energetic/health impairment process that links job demands with burnout; and (2) the motivational enhancement process that links job resources with engagement. Accordingly, job demands are related to various indicators of job strain including lack of energy and development of health problems and job resources are related to motivational indicators including engagement 
with or disengagement from work, and organizational commitment. Also, several job resources have been found to buffer the impact of job demands on employee well-being (burnout and to a lesser extent engagement). Additionally, although some studies failed to confirm the moderating role of personal resources (such as self-efficacy, organizational-based self-esteem and optimism) in the relationship between job demands and health outcomes (e.g., Xanthopoulou et al., 2007), other studies confirmed the suggested effect. For instance, self-efficacy was found to buffer the relation between emotional demands and emotional dissonance, and the relation between emotional dissonance and work engagement (Heuven, Bakker, Schaufeli, \& Huisman, 2006). On the contrary, personal resources have been found to partially mediate the relation between job resources and work engagement, suggesting that job resources foster the development of personal resources. A longitudinal study by Xanthopoulou, Bakker, Demerouti, and Schaufeli (2009) suggests that job resources predict personal resources and motivational outcomes, like work engagement; and that personal resources and work engagement, in turn, predict job resources. In light of these findings, the JD-R Theory suggests that personal resources might have a complex role in transforming the work environment into positive or negative outcomes.

\section{Evaluation of the JD-R Theory}

As already discussed, research findings largely support the JD-R Theory's assumptions. The theory has advanced the field of occupational (health) psychology by considering a broad range of demands, resources, and outcomes. As such, it is a heuristic and flexible theory. However, this openness and flexibility could also be the Achilles' heel of the theory, as this comes at the cost of specificity and the quality of its predictions. For instance, it may cause ambiguity as to whether a specific characteristic represents a demand or a resource or whether an outcome is health-related or motivational in nature. An example of such a characteristic is responsibility, as it is unclear whether a high level of responsibility for the outcomes of one's work represents a job demand or a job resource. Similarly, is satisfaction with working times a motivational or a health-related outcome? Perhaps the answers to these questions depend on the work context. Whereas the essence of job demands is that they consume energy because they have to be fulfilled, job resources initiate motivation and buffer the effects of job demands on outcomes. This further means that the absence or presence of a job demand like shiftwork is not motivating as the individual has no other choice than to deal with it. Moreover, the absence of a job resource, like autonomy, does not represent a demand. Rather it means that the voluntary initiation of action to achieve goals is not facilitated by the freedom of decision. Therefore, it is essential to have a clear idea of what the function/role of each job characteristic is when one applies the JD-R Theory. Another benefit of the JD-R Theory is that it has shown that two different underlying psychological processes can simultaneously play a substantial role in the development of health and motivation. 
However, there are a few shortcomings as well (for an overview, see Taris \& Schaufeli, 2014). First and foremost, the theory lacks specificity in explaining why certain job demands or resources exert their effects and on which target variable (i.e. health or motivational outcomes) they do so. Also, some of the job characteristics are difficult to categorize such as predictability of workload or cognitive demands. This implies that, apart from the two existing psychological processes, additional explanatory theoretical frameworks are necessary to argue why specific demands interact with specific resources to influence specific outcome variables.

\section{Individual Strategies in the JD-R The- ory}

The JD-R Theory started as a work psychological model, which was aimed at explaining how the working environment influences the well-being (burnout) of employees. However, the stimulus-organism-response idea does not really manage to explain what happens in reality, where work and individual characteristics are not related with each other and with outcomes in a linear way, relationships are dynamic and complex (Jacobi, 2002) and individuals play a more important role than only being passive receivers of external influences. The current paper will focus on three categories of individual strategies representing aspects of the individual that might be relevant to the JD-R Theory (see Figure 2). First, strategies that individuals use to deal directly with the unfavorable effects of job characteristics including actual or anticipated loss of resources. Some target the individual's relationship to the job (i.e., coping), while others focus on strengthening the individual's internal resources (i.e., recovery). A second category represents strategies that individuals use to maximize favorable effects, achieve their goals and avoid losses (i.e., self-regulation). Third, strategies that individuals apply to change their job characteristics directly such that the job is less demanding and more motivating (i.e. job crafting).

\section{Strategies to Deal with Unfavorable Effects of Job Characteristics}

According to the JD-R Theory when job demands are high and job resources are low it can be expected that employees develop burnout. Burnout has been defined as a longterm consequence of aversive working conditions characterized by the simultaneous experience of the symptoms of exhaustion and disengagement from one's job (Demerouti et al., 2001; Demerouti, Mostert, \& Bakker, 2010; Maslach, Schaufeli, \& Leiter, 2001). Exhaustion is defined as a consequence of intensive physical, affective, and cognitive strain, i.e., as a long-term consequence of prolonged exposure to certain job demands. Disengagement refers to distancing oneself from one's work object, work content, and work in general. From these definitions it becomes clear that inherent to the experience of burnout (as the most known outcome of the JD-R Theory) is the experience of diminished resources in terms of ability and willingness to invest effort in work tasks. Hobfoll (2001) described burnout as a result of the lack of resource gain following significant resource investment of time and energy. Employees who have already invested a substantial amount 
of time and energetic resources in their jobs may not be able to gain new resources that would help them manage the demands of their work and maintain optimal functioning in the long run. Investing their resources differently and maybe more effectively may protect them against (further) resource loss, help them recover from loss, and even help them gain new resources (a so-called gain cycle might develop; Hobfoll, 2001). Therefore, it is not surprising that burnout has been linked to strategies that individuals may use to deal with the diminished resources. The next section will present a brief overview on coping and recovery which represent perhaps the most known strategies to deal with stress and burnout. Both strategies share a common objective of addressing diminishing time and energetic resources and they are more reactive in nature.

\section{Coping strategies}

Applying a transactional approach to stress, Lazarus and Folkman (1984) defined coping as "those changing cognitive and behavioral efforts developed for managing the specific external and/or internal demands judged as exceeding or surpassing the individual's own resources" (p. 164). In the literature, several classifications of coping strategies can be found, which are made depending on the specific methods used or according to the precise objectives towards which coping strategies are directed. Billings and Moos (1981), for example, identified three methods of coping: a) active-cognitive, i.e., the management of the appraisal of stressful events such that they are less stressful; b) active-behavioral, i.e., the observable efforts aimed at managing a stressful situation; and c) avoidance, i.e., the refusal to face a problematic or stressful situation. On the basis of the objectives of coping, authors have made an essential distinction between coping oriented to the problem and coping oriented to the emotion (Lazarus \& Folkman, 1984). Problem-focused coping represents an attempt to respond directly to the stressful situation (which can be high demands or low resources), while emotion-focused coping consists of attempts to moderate the emotional response to stressful events (Cox \& Ferguson, 1991). In the more recent years other forms of coping have been introduced such as proactive coping.

Irrespectively of the specific coping form and in line with Lazarus and Folkman (1984), persons usually employ both task and emotion focused coping strategies. The former attempts some form of action directly targeted at dealing with the source of stress (adaptation of the environment), while the latter attempts to attenuate the emotional experience associated with stress (adaptation to the environment). Cox and Ferguson (1991) suggest that, like other individual differences, coping is often seen to function in the stress process as either "mediators of stress appraisal" or as "moderators of the stress-outcome relationship". As a mediator, coping can transmit the effect of stressors (job characteristics in the JD-R Theory) on the outcomes but do not qualitatively change the effect, whereas as a moderator it can change the direction or strength of a relationship between stress and responses 
(Cox \& Ferguson, 1991) or determine when certain responses to stress will occur.

The first way that coping can be integrated in the JD-R Theory is as a reaction to job demands and resources and as predictor of health and motivational outcomes. In line with this, coping has been characterized as "cognitive and behavioral efforts to manage (reduce, minimize, master, or tolerate) the internal and external demands of the person-environment transaction that is appraised as taxing or exceeding the person's resources" (Folkman et al, 1986). A failure to cope successfully (from excessive demands or lack of resources) is likely to lead to stress and negative health and organizational outcomes (Cox et al., 2000). There is evidence that coping is a reaction to high demands and low resources. In a longitudinal study with social workers, Koeske (1993) found that active coping strategies provided greater capacity for coping with difficult situations at work. Coping, in its turn, has been found to predict motivational and health related outcomes, like burnout. Thornton (1992), for example, found a statistically significant association between avoidance coping and burnout in a sample of workers at a psychiatric clinic. Chan and Hui (1995) found that avoidance coping was positively related to the three components of burnout in a group of secondary school teachers.

However, more studies seem to have examined the coping strategies that individuals used in reaction to their burnout experiences. Leiter (1993) posited that outcomes reflecting withdrawal tendencies (e.g., avoidance coping, low job involvement, and desire to quit) are more related to either emotional exhaustion or depersonalization, whereas outcomes reflecting positive self-efficacy (e.g., active coping) are more related to personal accomplishment. Consistent with Leiter's (1993) model, the findings of the meta-analysis of Lee and Ashforth (1996) revealed that the three dimensions of burnout were differentially associated with coping strategies. Emotional exhaustion and depersonalization were weakly associated with active coping, reflecting the underuse of such a coping behavior or the lack of its effectiveness and subsequent abandonment. Conversely, personal accomplishment was strongly related to active coping, suggesting that a problem-focused response and a positive self-appraisal may be mutually reinforcing (Lazarus \& Folkman, 1984; cf. Leiter, 1991). Similarly, Yela (1996) reported that the greater the feelings of emotional exhaustion, the more likely these professionals were to use strategies coinciding with a passive form of coping, including strategies based on behavioral and mental disconnection from the situation, concentrating on one's emotions and venting one's feelings when faced with difficult or stressful events.

Recently a more positive form of coping has gained research attention, namely proactive coping. Proactive coping represents an effort to build up general resources that facilitate promotion toward challenging goals and personal growth (Angelo \& Chambel, 2014). Angelo and Chambel (2014) found 
that proactive coping partially mediated the relationship between job demands and burnout, as well as the relationship between job resources and work engagement. Moreover, whereas both job demands and job resources were positively related to proactive coping, proactive coping was negatively related to burnout and positively related to work engagement.

Next to the mediating role, several studies have found that coping plays a moderating role between job characteristics and well-being. For instance, Siu et al. (2002) found that the relationship between work stress (indicating high job demands and low job resources) and physical well-being was positive among managers in China and Hong Kong who employed more support coping (e.g., resort to hobbies and pastimes). Additionally, proactive coping has been found to play the role of a moderator in the JD-R Theory. Specifically, Searle and Lee (2015) found in a cross-sectional study that proactive coping moderated relations between challenge demands and work engagement, as well as relations between challenge demands and burnout. Daniels (1999) even examined whether the three-way interaction between job demands, job resources and coping is predictive of well-being. The results indicated that in certain conditions job control and social support do enhance coping efforts. For problem-focused coping and emotion-focused coping, the results indicated in general that control and support enable coping to buffer the effects of job demands on well-being, up to a certain threshold for job demands. Once this threshold was exceeded, job demands had a stronger negative relationship with well-being. The results indicated that job control enhances moderate levels of both appraisal and cognitive-escape-focused coping, but not extreme levels of these forms of coping. Finally, there was some evidence that social support may enhance very high levels of appraisal-focused coping, but in general appraisal-focused coping is more effective at low levels of support.

Next to the different ways of coping researchers have also considered the effectiveness of coping. Cox (1987) warns that in reality, the problem-solving process in a stress setting is unlikely to be so rational. For example, appraisal and coping processes may not be open to conscious evaluation, and may be carried out with bias, insufficient information, to appear irrational or counterproductive, with consideration of a limited number of solutions, and with little or no attention paid to feedback or past learning. Cox (1987) argues that these problems could be what make the difference between successful and unsuccessful problem-solving episodes. Aluja Fabregat, Blanch Plana, and Biscarri Gassio (2003) suggested that the effectiveness of coping depends on the situation. Specifically, although it seems evident that strategies oriented to the problem are much more effective for coping with stressful situations than those oriented to the emotion and to avoidance (Roger, Jarvis, \& Najarian, 1993; Hart, Wearing \& Heady, 1995), the effectiveness of strategies oriented to the 
problem has been found to depend on effective control of the potential stressors of the environment and individual emotions (Folkman, 1984; Ito \& Brotheridge, 2001). On the other hand, persistent use of problem-focused coping strategies when there are few possibilities of controlling and/ or changing the environmental stressors may exacerbate the undesirable effects of work stress (Schaubroek \& Merritt, 1997; de Rijk, Le Blanc, Schaufeli, \& de Jonge, 1998). At the same time, it has been pointed out that in less controllable circumstances, strategies oriented to the problem in combination with strategies oriented to avoidance may be useful for improving adaptation and wellbeing (Aluja Fabregat et al., 2003). In this way, flexibility in utilized coping strategies would be adaptive rather than maladaptive, that is, coping oriented to the problem would be adaptive in controllable situations, whilst coping oriented to avoidance would be adaptive in situations difficult to control (Latack, 1986; Koeske, 1993). In this line, Cheng (2001) concluded that both perception of control and objective controllability of the stressors would play a key role in the achievement of effective coping.

Taken together, coping can be integrated in the JD-R Theory, both as a mediator and a moderator of the health impairment and the motivational process. More specifically, coping is a reaction to high job demands and lack of job resources and a predictor of health and motivational outcomes. Moreover, health and motivational outcomes are predictors of coping indicating a reciprocal relationship between coping and outcomes. Additionally, coping is found to moderate the relationship between job demands and job resources on the one hand and health and motivational outcomes on the other hand. More importantly, what seems to matter more is whether the applied coping attempt was effective for the situation that the individual was aiming to deal with. It is suggested that whether or not the individual has control of the situation seems to determine the effectiveness of the applied coping strategy.

\section{Recovery from Work}

Perhaps the most relevant strategy that individuals may use to deal directly with the unfavorable effects of job demands is to recover from work. Recovery occurs after strain when the stressor is no longer present (Sonnentag \& Fritz, 2007). It represents the process that repairs the negative strain effects. More specifically, recovery refers to the process during which an individual's functioning returns to its pre-stressor level and in which strain is reduced (Sonnentag $\&$ Natter, 2004). In other words, recovery refers to activities that are able to reduce fatigue and restore a status of physiological and psychological performance readiness. This makes recovery particularly relevant for regulating the levels of energy and reducing the levels of exhaustion. This makes recovery particularly relevant for the health impairment process of the JD-R theory.

According to Meijman and Mulder (1998), effort expenditure at work is unavoidably associated with, in principle 
adaptive, acute load reactions (e.g., accelerated heart rate, elevated blood pressure levels, and fatigue). Under optimal circumstances, the stress-related acute load reactions return to pre-stressor levels during after-work hours, and recovery is completed before the next working period starts. However, when the stress-related acute load reactions prolong or re-occur during after-work hours (i.e., sustained sympathetic activation), recovery is incomplete (Geurts \& Sonnentag, 2006). Consequently, the worker will start the next working period while being in a suboptimal condition and will have to invest compensatory effort in order to perform adequately at work. Prolonged exposure to work demands (e.g., daily overtime work, ruminate about work problems) that strain the same psycho-physiological systems that were already activated on the job also after work may lead to a total breakdown (Geurts \& Sonnentag, 2006). Particularly when job demands are high, employees will be more inclined to work longer or more intensive in order to fulfil them and to avoid a possible backlog. When they recover, they can avoid creating load effects which strain their psychophysiological system the next day when they start work. Failure to recover means that the individual starts the working day with feelings of tiredness, which accumulated in the long term may lead to exhaustion.

What recovery strategies have been found to be successful in reducing strain and the risk of exhaustion or health problems? Among other things, Sonnentag und
Fritz (2007) have discriminated between psychological detachment from work during non-work time, relaxation and mastery as recovery experiences that may be relevant for burnout. Psychological detachment means that the individual stops thinking about work and disengages his/ herself mentally from work. Lack of detachment has been associated with higher exhaustion and lower need for recovery (Sonnentag, Kuttler \& Fritz, 2010). Moreover, over time psychological detachment mediated the relation between job stressors on the one hand and emotional exhaustion and need for recovery on the other hand (Sonnentag, Binnewies, \& Mojza, 2010). Furthermore, Sonnentag and Fritz (2007) found that relaxation is negatively correlated with health complaints, exhaustion, sleep problems, and need for recovery. This indicates that low-effort activities require hardly any effort on the part of the individual and therefore pose no demands on the psychobiological system (Sonnentag \& Natter, 2004); therefore, they help individuals reduce their levels of exhaustion on days that these levels are high. Mastery experience refers to pursuing mastery-related off-job activities (e.g. taking a language class, or learning new sports) that offer an individual challenges or opportunities to learn new skills (Sonnentag \& Fritz, 2007). The empirical evidence available so far suggests that mastery experiences are negatively related to emotional exhaustion, depressive symptoms, and need for recovery (Sonnentag \& Fritz, 2007), and positively to (morning) positive activation (Sonnentag, Binnewies, \& Mojza, 2008). 
Next to these specific relationships, recovery has already been studied in within the JD-R Theory as a mediator. Job demands can be seen as factors that inhibit recovery, whereas job resources facilitate recovery (Demerouti, Bakker, Geurts \& Taris, 2009). More specifically, Kinnunen, Feldt, Siltaloppi, and Sonnentag, (2011) suggested that recovery experiences-especially psychological detachment and relaxation - partially mediate the relationship between job demands and fatigue at work, whereas recovery experiences-especially mastery and control-partially mediate the relationship between job resources and work engagement. The results showed that psychological detachment fully mediated the effects of job demands on fatigue at work and mastery partially mediated the effects of job resources on work engagement.

Recovery has also been found to play a moderating role in the JD-R Theory. More specifically, Siltallopi, Kinnunen and Feldt (2009) showed that recovery experiences psychological detachment and mastery in particular - not only had direct favorable effects on occupational well-being but also interactive effects. Specifically, they showed that psychological detachment and mastery were protective mechanisms against increased need for recovery in a situation of lack of job control. Moreover, relaxation protected against increased job exhaustion under high time demands. Similarly, psychological detachment from work and relaxation are found to buffer the negative impact of role conflict on health-relat- ed outcomes (anxiety, somatic symptoms, bullying experiences) (Moreno-Jiménez, Rodríguez-Muñoz, Sanz-Vergel, \& Garrosa, 2012).

Overall, findings suggest a differential pattern of the recovery experiences in the health impairment and motivational process proposed by the JD-R model. Although recovery has mainly been studied within the health impairment process, recent research seems to suggest that it is also relevant for the motivational process. Whereas both mediating and moderating role of recovery have been examined within the JD-R model, such roles have not been confirmed for all recovery experiences and various possible outcomes related to the two processes.

\section{Strategies to Maximize Favorable Effects}

Whereas the previous section referred to more reactive strategies to deal with stress and burnout to address diminishing time and energetic resources, the current section focusses on strategies that individuals use to maximize favorable effects, achieve their goals and avoid losses (i.e., self-regulation). Self-regulation refers to the regulation of the self by the self, and involves aligning thinking, feelings and behavior to some consciously desired goal (Forgas, Baumeister \& Tice, 2009). In this way, self-regulation concerns how individuals take effective action, make effective decisions, and manage their motivation and emotions especially in the face of setbacks (O’Shea, Buckley \& Halbesleben, 2017). 


\section{Self-regulation}

Individuals have the ability to control and regulate motivation, cognition, affect and behaviors. The ability to manage internal states and alter behavioral responses is commonly known as self-regulation (Muraven \& Baumeister, 2000), which allows individuals to meet deadlines, persevere through adversity, resist temptations, and be kind to others even when others are difficult. Self-regulation is the capacity to alter actions to conform to morals, ideals, values, and social expectations in order to pursue long-term goals (Baumeister, Vohs, $\&$ Tice, 2007). Mackey and Perrewe (2014) suggest that self-regulation is a key mechanism to understanding why some individuals are able to learn and adapt to stressors effectively, and others are unable to do so effectively. Self-regulation may explain why behaviors in response to specific events may vary across time and contexts. It enables individuals to restrain from inappropriate behaviors, such as aggressive acts toward a supervisor when angered and to make an inner strength or energy available to manage demands and bring about positive outcomes. On the constructive side, self-regulation has been associated with good adjustment and positive psychological states (Tangney, Baumeister, \& Boone, 2004). On the destructive side, poor self-regulation has been associated with increased vulnerability, substance-abuse, and eating disorders (Tangney et al., 2004). When individuals engage in self-regulation (e.g., resisting the temptation to aggress against a supervisor), the amount of this personal resource available is reduced. The state of being low in self-regulatory resources due to previous self-regulation is known as "ego depletion" (Baumeister et al., 2007).

Mackey and Perrewe (2014) have integrated self-regulation in a work stress model. Specifically, they suggest that self-regulation moderates the relationship between organizational stressors or demands and job strain or well-being. They argue that coping with stressors requires individuals to utilize self-regulatory resources in order to stop or buffer inappropriate coping behaviors. In this way, appropriate self-regulation will buffer poor action tendencies and actual behaviors (e.g., yelling at a coworker when angry). However, self-regulation, if used frequently, can deplete a limited resource. If organizational stressors and subsequent emotions are managed successfully using self-regulation initially, self-regulation may be depleted over time (cf. ego depletion) if the stressors are not removed. Depleted self-regulation resources may be replenished in different ways. Regular exertions of self-regulation actually can improve individuals' self-regulation over time and make them more resistant to self-regulation depletion. Mackey and Perrewe (2014) argue that personal and organizational resources may help to either prevent ego depletion or to enhance self-regulation once depleted. Self-regulation cannot proceed without a commitment to standards or goals because self-regulation is the effortful attempt to alter one's behavior so as to meet a standard/goal. Resources help per definition goal achieve- 
ment by offering information about how to achieve goals (e.g., role clarity or leadership). Thus, resources, such as role clarity, should have a positive association with self-regulation. Personal resources such as political skills and self-monitoring are suggested by Mackey and Perrewe (2014) to influence self-regulation directly. Moreover, resources, such as resiliency and social support (e.g., talking with coworkers in the same situation) or autonomy (e.g., deciding yourself which demand to fulfil first), may have a direct impact on lessening ego depletion or replenishing the self-regulation resource.

Existing empirical evidence supports that self-regulation both moderates and mediates the relationship between job demands and health related outcomes. For instance, Schmidt, Neubach and Heuer (2007) found that cognitive control deficits (self-reported failures in perception, memory, and action) mediated the relationship between self-control demands and the burnout dimensions of emotional exhaustion and depersonalization providing clear evidence of the vulnerability hypothesis of cognitive control deficits as an indicator of self-regulation. Moreover, Diestel and Schmidt (2009) examined whether self-control (impulse control, resisting distractions, and overcoming inner resistances) could moderate the relationships between qualitative workload (concentration requirements) and quantitative work load (work pressure) and exhaustion as well as anxiety. Significant interaction effects between qualitative workload and impulse control as well as between both of the workload variables and resisting distractions were found on both exhaustion and anxiety. Similarly, Brenninkmeijer, Demerouti, Le Blanc and van Emmerik (2010) examined whether regulatory focus moderated the motivational and health impairment process of the JD-R theory. Regulatory focus theory (Higgins, 2000) distinguishes between two regulatory foci among individuals. When promotion focused, individuals are motivated by growth and development needs, have strong ideals, and prefer gain to the avoidance of losses. When prevention focused, individuals are responsive to security needs, the responsibility for safety and protection, have strong emphasis on obligations, and prefer the avoidance of loss to gains. Results confirmed that detrimental effects of job demands (i.e., workload, interpersonal conflict) on emotional exhaustion were more pronounced among individuals with a strong prevention focus. Moreover, the favorable effects of job resources (i.e., autonomy, social support) on motivational outcomes (i.e., work engagement, organizational commitment and job satisfaction) were more pronounced among individuals with a weak rather than high promotion focus (as was expected).

Finally, Demerouti, Bakker and Leiter (2014) investigated whether self-regulation (regulatory focus) can help employees to maintain their performance (i.e., task performance, adaptivity to change) at acceptable levels despite experiencing burnout (i.e., exhaustion, disengagement). They found 
that compensation (i.e., organizing substitute means to reach goals and to maintain a high level of functioning) was the most successful strategy in buffering the negative associations of disengagement with supervisor-rated task performance and both disengagement and exhaustion with supervisor-rated adaptivity to change. In contrast, the selection strategy (i.e., setting goals and deciding on goal priorities) exacerbated the negative relationship of exhaustion with supervisor-rated adaptivity to change.

Taken together, self-regulation seems to play an important role in the relationships suggested by the JD-R Theory. Although various studies used different indicators of self-regulation, it seems that self-regulation plays both a moderating and mediating role in both processes. There is, however, more empirical evidence on the moderating role of self-regulation. It is particularly involved in the process through which job characteristics influence health and motivational outcomes but it also seems to moderate the impact of health and motivational outcomes on performance outcomes.

\section{Strategies to Change Job Characteristics}

Up to now, the focus was on strategies that individuals use to deal with actual loss or the threat of diminishing resources by changing something in themselves. Individuals can or even should find ways to change or adjust their work (characteristics) such that they avoid losses and maximize outcomes. This comes close to active coping but differs in that coping represents a reaction to stressors, while the driver of the main strategy present- ed here, job crafting, is the search for meaning and for a motivating and healthy work environment.

\section{Job Crafting}

Job crafting (Wrzesniewski \& Dutton, 2001) represents actions employees take so as to alter the task boundaries of a job (i.e., type or number of activities), the cognitive task boundaries of a job (i.e., how one sees the job), and the relational boundaries of a job (i.e., whom one interacts with at work). Examples of job crafting could be hospital cleaners starting to interact with patients (Wrzesniewski \& Dutton, 2001) or a police officer who organizes a sport event to increase the physical condition of herself and her colleagues. In order to describe the actions that are performed by job crafters in more detail, recent literature (Petrou, Demerouti, Peeters, Schaufeli \& Hetland, 2012; Tims, Bakker, \& Derks, 2012) has used the JD-R Theory (Demerouti et al., 2001) and the two-dimensional work stressor framework by Podsakoff, LePine and LePine (2007) as conceptual frameworks. These two frameworks distinguish job characteristics into hindering job demands (i.e., the demanding aspects of a job which require physical and psychological effort), challenging job demands (i.e., demanding aspects of a job that have the potential to promote employee growth and development) and job resources (i.e., job aspects that are functional for achieving work goals and can eliminate the costs of the demands). Following this stream of literature, job crafting refers to voluntary self-initiated employee behaviors targeted 
at seeking resources (i.e., asking a manager or colleagues for advice), seeking challenges (i.e., asking for more responsibilities), and reducing hindering demands (i.e., eliminating emotionally, mentally or physically demanding job aspects). Following Wrzesniewski and Dutton (2001), Petrou et al. (2012) suggested that even in the most stable environments with detailed job descriptions and clear work procedures, individuals can and do adjust the tasks they perform and mobilize the resources they need to carry out their tasks successfully.

More specifically, seeking resources (e.g., performance feedback, advice from colleagues or the manager, maximizing job autonomy) can be a form of coping with job demands or achieving goals and completing tasks (Petrou et al., 2012). Hobfoll (2001) also suggested that a basic human motivation is directed towards the accumulation of resources, which are important for the protection of other valued resources. At the workplace, this can take the form of proactive behavior with positive outcomes for employee motivation and well-being (Salanova \& Schaufeli, 2008). Thus, by successfully seeking job resources, employees accumulate resources and expand their current resource pool.

Seeking challenges may include behaviors such as pursuing new stimulating tasks at work, keeping busy during one's working day, or asking for more responsibilities once assigned tasks have been completed. Csikszentmihalyi and Nakamura (1989) argued that when individuals engage in activities offering opportunities for growth, they seek challenges to maintain motivation and avoid boredom. Job demands do not play an exclusively dysfunctional role (Demerouti et al., 2001). Podsakoff et al. (2007) suggested that there are some demands that have a positive effect on employee job satisfaction and commitment. These demands have been called challenge stressors.

Reducing job demands represents a way to reduce hindrances, for example, by minimizing the emotionally, mentally, or physically demanding aspects of one's work and reducing one's workload or time pressure (Petrou, et al., 2012; Tims et al., 2012). Unlike challenging job demands, hindering job demands are demanding job aspects that employees appraise as potentially constraining their development and performance (Podsakoff et al. 2007). Reducing job demands is not an extensively studied employee behavior. Avoidance coping techniques, which could involve similar behaviors, are linked with impaired mental health and social functioning (Endler \& Parker, 1994), and should relate to individuals' emotional numbness and unawareness of what causes them stress (Roth \& Cohen, 1986).

What is the role of job crafting in the JD-R Theory? One of the first studies on job crafting indicated that it related to both job demands and job resources. Specifically, Petrou et al. (2012) found that the combination of high daily work pressure and high daily autonomy (i.e., active jobs) was associated with higher day-level seeking resources and lower day-level reducing demands. Furthermore, they found that day-level seeking challenges (but not resources) was positively 
associated with day-level work engagement, whereas day-level reducing demands was negatively associated with day-level work engagement. Job demands and resources have also been found to have main effects on job crafting. For instance, Kanten (2014) found that skill variety and feedback were positively related to job crafting, whereas task significance and autonomy dimension were unrelated to job crafting. However, there are studies showing that job crafting is not significantly predicted by job characteristics. Niessen, Wesseler and Kostova (2016) found that task interdependency and job autonomy were unrelated over time.

Job crafting has been examined both as a predictor and as an outcome of job demands and resources but also of health and motivational indicators. Specifically, Tims, Bakker, and Derks (2013) with their longitudinal study showed that employees who crafted their job resources in the first month of the study reported an increase in their structural and social resources over the course of the study (2 months). This increase in job resources was negatively related to burnout and positively to engagement and job satisfaction. More specifically, it was shown that increasing structural job resources (i.e., autonomy, variety, and opportunities for development) as a form of job crafting was negatively directly related to burnout and indirectly through the perception of structural job resources themselves. Additionally, increasing social resources (i.e., social support, feedback, and coaching) as a form of job crafting was indirectly negatively related to burn- out through the perception of social job resources. Crafting job demands did not result in a change in job demands, but results revealed direct effects of crafting challenging demands (i.e., workload) on decreases in burnout and increases in work engagement. In this study, crafting hindering demands (i.e., cognitive demands and emotional demands) was unrelated to any of the outcomes. These findings highlight the importance of mobilization of job resources (both structural and social) in order to diminish the risk to burnout.

Partly similar findings are reported by Petrou, Demerouti, and Schaufeli (2013), who used a longer time frame of one year between the measures and a sample that was undergoing organizational change. In this study, seeking resources was unrelated to exhaustion but seeking challenges did have a positive implication; namely it contributed to lower levels of exhaustion. In other words, an approach of actively confronting new demanding aspects of the job is associated with lower rather than higher strain. Furthermore, Petrou et al. (2013) found an interesting pattern of relationships between reducing demands and exhaustion. Employees who attempted to reduce their demands reported higher exhaustion, a state that, in its turn, led to further decreasing demands, highlighting that reducing demands is not an effective strategy. Similar findings are also reported by the diary study of Demerouti, Bakker, and Halbesleben (2015), who further found that daily seeking resources positively affected daily performance by increasing daily job autonomy and work 
engagement whereas reducing demands negatively affected performance by reducing daily work and daily exhaustion. A recent study among airline pilots (Demerouti, Veldhuis, Coombes \& Hunter, in press), not only confirmed the assumptions of the JD-R Theory but it also showed that job demands were detrimental to simulator training performance because they made pilots more exhausted and less able to craft their job, whereas job resources had a favorable effect because they reduced feelings of disengagement and increased job crafting. In this way, the study showed why burnout is related to worse performance because it impairs job crafting behavior.

Job crafting has more often been examined as a mediator rather than as a moderator in the JD-R Theory. However, it would make sense to suggest that job crafting moderates the relations of the health impairment and the motivational process. Only Bakker (2018) found recently that the interaction between job crafting and work engagement was related to several work characteristics including opportunities for development, performance feedback bureaucracy and role ambiguity. It is expected that future studies will provide more insight into the interacting effects of job crafting within the JD-R Theory uncovering the situational specificity of job crafting behavior.

Thus, individuals seem to use bottom-up, job crafting strategies to change their job characteristics such that they become less hindering and more motivating and challenging. The limited empirical evidence seems to suggest that the mobi- lization of resources and challenges by the individual seems to reduce unfavorable outcomes, such as burnout, and increase favorable outcomes, such as work engagement. Conversely, when individuals reduce their job demands, they seem to enter into a negative spiral in which reducing demands is related to more exhaustion, which over time is related to more reducing demands. Thus, specific job crafting behaviors seem to diminish burnout. However, burnout does not seem to stimulate job crafting, which shows that individuals need to have the energy and motivation available to adjust their jobs to their preferences. Although we lack evidence about the moderating effects of job crafting in the JD-R theory, job crafting is the strategy that has more consistently been shown to influence job demands and resources.

\section{Conclusions and Future Research}

The goal of this paper was twofold: (i) to present the key assumptions of the JD-R Theory, an overview of empirical evidence as well as an evaluation of the theory, (ii) to discuss the role of the three categories of individual strategies in the JD-R Theory. Overcoming the restricted, static, and one-sided early models of stress and motivation, JD-R Theory suggests that job characteristics can be organized in two categories: job demands and job resources. These two categories of work characteristics can be found in virtually every job and are therefore important because they are initiators of two different processes: the health impairment and motivational process. Not only do demands and resources 
have unique effects on employee health and motivation; they also have joint (interactive) effects on employee well-being. Rather than being mechanistic, the JD-R model suggests that personal resources are also important predictors of motivation, and can buffer unfavorable effects of job demands. Although there is strong empirical evidence for both processes, there are still several important issues that have to be considered when evaluating the theory's status. The most distinctive feature of the JD-R Theory is its generality and flexibility, hence its popularity. However, the theory's openness and flexibility come at the cost of specificity of predictions.

Bakker and Demerouti (2017) discussed promising avenues for future research and theoretical innovations within the JD-R Theory. First, they suggested examining whether the hypothesized constellations of working conditions (interactions) will have the same favorable or unfavorable effects on employee well-being and outcomes over time, e.g., how long can job resources buffer the effect of high demands. Second, a more rigorous test of causality is required and investing more effort in experimentally manipulating job characteristics (e.g., in a field experiment/intervention) to see whether such modifications have the predicted effects is suggested. Third, next to personal resources, also personal demands (i.e., the requirements that individuals set for their own performance and behavior that force them to invest effort) such as performance expectations, perfectionism, workaholism, should be more systemati- cally included in the JD-R theory. Fourth, integrating more objective indicators of the prevailing job demands and resources, and of the possible employee and organizational outcomes, including physiological (health) and economical indictors will make the theory more impactful. Fifth, it is important to investigate how leadership behaviors change from day to day, and how changes in these behaviors affect employee work engagement and job performance, through their impact on daily job demands and resources. Sixth, in order to grasp the experience of work and understand the interplay between work events, situations or characteristics and well-being and motivation, we need to focus on work occasions, performance episodes, and discrete behaviors. Seventh, integrating multilevel constructs (on the team or organizational level) in JD-R research can help to capture the complexity of organizational phenomena and develop more sophisticated theoretical models and more effective interventions. Finally, Bakker and Demerouti (2017) suggested integrating individual strategies in the JD-R Theory, which is the focus of the current paper.

More specifically, this paper examined the role of strategies that individuals use to alter the impact of job characteristics so that the unfavorable effects are minimized whereas the favorable ones are maximized. Three forms of strategies were discussed including strategies that individuals use to (i) deal directly with the unfavorable effects of job characteristics which may be actual or anticipated loss of resources namely 
coping and recovery; (ii) maximize favorable effects, achieve their goals and avoid losses, i.e., self-regulation and (iii) change their job characteristics directly such that the job is less demanding and more motivating i.e., job crafting. It was shown that individual strategies can be integrated in the JD-R Theory, both as a mediator and a moderator of the health impairment and the motivational process. There was sufficient evidence indicating that individual strategies mediate the effects of job demands and job resources on health and motivational outcomes, respectively. Of the strategies reviewed, only job crafting was consistently found to influence job demands and resources thus explaining the reverse effects of well-being indicators on job characteristics. Moreover, health and motivational indicators were found to influence the focal strategies, highlighting their importance as ways to deal with diminishing resources or to maximize favorable outcomes. Moreover, coping, recovery and self-regulation were shown to moderate the impact of job demands and resources on health outcomes and motivational outcomes. This role of individual strategies is very important as it highlights that individuals can do something to alter the way that the work environment influences them.

To this end, more research is necessary to uncover several unresolved issues regarding individual strategies (Demerouti, 2015). First, although several strategies were reviewed, it is by no means plausible that individuals use only the presented strategies. Other possible strategies that may be relevant for JD-R theory are strength use (van Woerkom, Oerlemans, \& Bakker, 2016) and proactive vitality management (Op den Kamp, Tims, Bakker, \& Demerouti, in press). Future research should expand our knowledge on what the other possible strategies are that individuals use to avoid burnout or minimize its effects. Second, we still do not know how long the effects of these strategies last. Considering the fluctuating character of the utilized strategies as well as the insight that the effectiveness of the applied strategy seems to depend on the situation, it is suggested that diary research that follows individuals daily during several measurement moments close to the natural context in which they operate (Ohly, Sonnentag, Niessen \& Zapf, 2010) might be a useful way to study individual strategies. Third, as all studies presented in this review examined the effect of one unique strategy, an emerging question is whether the combined use of the strategies is more effective than the employment of a single strategy. This necessitates a shift beyond the tendency to focus on one-causeone-effect relationships to examining combinations of predictors (Kahn \& Byosiere, 1992). Fourth, it is essential to know how individuals can be helped to learn to use effective strategies. To this end, intervention studies are necessary. Such studies have shown that individuals can be trained to develop effective coping strategies in terms of stimulating support-seeking behavior (Peterson, Bergström, Samuelsson, Åsberg, \& Nygren, 2008), to learn how to recovery from work more effectively (Hahn, Binnewies, Sonnentag \& Mojza, 2011), 
and to learn how to craft their job (Gordon, et al., 2018; van den Heuvel, Demerouti \& Peeters, 2015).

The strategies discussed should not be seen as replacing top-down, organizational approaches (e.g., job redesign, optimization of workflow, reduction of work hazards) that aim to optimize the work environment and working conditions such that the risk of diminished health and motivation is minimized. Rather, they should be viewed as strategies that occur simultaneously with organizational approaches and are generally spontaneous and unattended, e.g., job crafting (Demerouti, 2015). Therefore, it is essential that organizations and individuals are aware of the effectiveness of the different individual strategies and inform individuals about the importance of such strategies such that they make more effective choices. Moreover, they should motivate them to use the effective strategies for their current and future health and well-being, and teach them how to do so by providing them training possibilities. The hope is that JD-R Theory will be used to guide future research and practice such that employees can work in healthier, more engaging, and more productive working environments.

\section{References}

Aluja Fabregat, A., Blanch Plana, A., \& Biscarri Gassió, J. (2003). Burnout syndrome and coping strategies: a structural relations model. Psychology in Spain, 7, 46-55.

Ângelo R. P. \& Chambel M.J. (2014) The role of proactive coping in the Job Demands-Resources Model: A cross-section study with firefighters. European Journal of Work and Organizational Psychology, 23, 203-216.

Bakker A. B. (2018). Job crafting among health care professionals: The role of work engagement. Journal of Nursing Management, 26, 321-331.

Bakker, A. B., \& Demerouti, E. (2007). The job demands-resources model: State of the art. Journal of Managerial Psychology, 22, 309-328.

Bakker, A. B., \& Demerouti, E. (2014). Job Demands-Resources theory. In C. Cooper \& P. Chen (Eds.), Wellbeing: A complete reference guide (pp. 37-64). Chichester, UK: Wiley-Blackwell.

Bakker, A. B., \& Demerouti, E. (2017). Job demands-resources theory: Taking stock and looking forward. Journal of Occupational Health Psychology, 22, 273-285.

Bakker, A. B., Demerouti, E., \& Euwema, M. C. (2005). Job resources buffer the impact of job demands on burnout. Journal of Occupational Health Psychology, 10, 170-180.

Bakker, A. B., Hakanen, J. J., Demerouti, E., \& Xanthopoulou, D. (2007). Job resources boost work engagement particularly when job demands are high. Journal of Educational Psychology, 99, 274-284.

Baumeister, R. F., Vohs, K. D., \& Tice, D. M. (2007). The strength model of self-control. Current Directions in Psychological Science, 16, 351-355.

Billings, A. G. \& Moos, R. H. (1981). The role of coping responses and social resources in attenuating the stress of life events. Journal of Behavioral Medicine, 4, 139-157. 
Brenninkmeijer, V., Demerouti, E., le Blanc, P. M., \& Hetty van Emmerik, I. J. (2010). Regulatory focus at work: The moderating role of regulatory focus in the job demands-resources model. Career Development International, 15(7), 708-728.

Caplan, R. D., Cobb, S., French, J. R. P., van Harrison, R., \& Pinneau, S. R. (1975). Job demands and worker health, main effects and occupational differences. Washington, D.C.: National Institute for Occupational Safety and Health.

Chan, D. W. \& Hui, E. K. P. (1995). Burnout and coping among Chinese secondary school teachers in Hong-Kong. British Journal of Educational Psychology, 65, 15-25.

Cheng, C. (2001). Assessing coping flexibility in real life and laboratory settings: A multimethod approach. Journal of Personality and Social Psychology, 80, 814-833.

Cox, T. (1987). Stress, coping and problem solving. Work \& Stress, 1, 5-14.

Cox, T., \& Ferguson, E. (1991). Individual Differences, Stress and Coping. In C.L. Cooper, \& R. Payne (Eds.). Personality and Stress: Individual Differences in the Stress Process. Wiley.

Cox, T., Griffiths, A. \& Rial-Gonzalez, E. (2000). Research on Work-Related Stress, Office for Official Publications of the European Communities: Luxembourg.

Crawford, E. R., LePine, J. A., \& Rich, B. L. (2010). Linking job demands and resources to employee engagement and burnout: A theoretical extension and meta-analytic test. Journal of Applied Psychology, 95, 834-848.

Csikszentmihalyi, M., \& Nakamura, J. (1989). The dynamics of intrinsic motivation: a study of adolescents. In C. Ames and R. Ames (Eds.), Research on motivation in education (volume 3, pp. 45-71). Orlando, Fl: Academic Press.

Cummings, E. M., Greene, A. L., \& Karraker, K. H. (1991). Life-span developmental psychology: Perspectives on stress and coping. Hillsdale, NJ: Lawrence Erlbaum Associates.
Daniels, K. (1999). Coping and the job demands-control-support model: An exploratory study. International journal of stress management, 6, 125-144.

Demerouti E., Bakker, A. B., Nachreiner, F., \& Schaufeli, W. B. (2001). The Job Demands-Resources model of burnout. Journal of Applied Psychology, 86, 499-512.

Demerouti, E. (2015). Strategies used by individuals to prevent burnout. European Journal of Clinical Investigation, 45, 1106-1112.

Demerouti, E., \& Bakker, A. B. (2011). The Job Demands-Resources model: Challenges for future research. South African Journal of Industrial Psychology, 37, 1-9.

Demerouti, E., Bakker, A. B., \& Leiter, M. (2014). Burnout and job performance: The moderating role of selection, optimization, and compensation strategies. Journal of occupational health psychology, 19(1), 96- 107.

Demerouti, E., Bakker, A. B., Geurts, S. A. and Taris, T. W. (2009). Daily recovery from work-related effort during non-work time. In S Sonnentag, P. Perrewe, \& D. Ganster, (Eds.) Current perspectives on job-stress recovery (85-123). Bingley, UK: Emerald.

Demerouti, E., Bakker, A. B., Geurts, S. A. E., \& Taris, T.W. (2009). Daily recovery from work-related effort during non-work time. In S. Sonnentag, P.L. Perrewé \& D.C. Ganster (Eds.), Current perspectives on job-stress recovery: Research in occupational stress and well being (Vol. 7, p. 85-123). Bingley, UK: JAI Press.

Demerouti, E., Bakker, A. B., Nachreiner, F., \& Schaufeli, W. B. (2001). The job demands-resources model of burnout. Journal of Applied psychology, 86, 499-512.

Demerouti, E., Bakker, A.B., \& Halbesleben, J. (2015). Productive and Counterproductive Job Crafting: A Daily Diary Study. Journal of Occupational Health Psychology, 20, 457-469. 
Demerouti, E., Le Blanc, P. M., Bakker, A. B., Schaufeli, W. B., \& Hox, J. (2009). Present but sick: a three-wave study on job demands, presenteeism and burnout. Career Development International, 14, 50-68.

Demerouti, E., Mostert, K., \& Bakker, A. B., (2010). Burnout and work engagement: A thorough investigation of the independency of both constructs. Journal of Occupational Health Psychology, 15, 209-222.

Diestel, S. \& Schmidt, K.-H. (2009). Mediator and moderator effects of demands on self-control in the relationship between work load and indicators of job strain, Work \& Stress, 23(1), 60-79.

Endler, N. S., \& Parker, J. D. (1994). Assessment of multidimensional coping: Task, emotion, and avoidance strategies. Psychological Assessment, 6, 50-60.

Folkman, S. (1984). Personal control and stress and coping processes: A theoretical analysis. Journal of Personality and Social Psychology, 46, 839-852.

Folkman, S., Lazarus, R.S., Gruen, R.J., \& DeLongis, A. (1986). Appraisal, coping, health status, \& psychological symptoms. Journal of Personality and Social Psychology, 50, 571-579.

Forgas, J. P., Baumeister, R. F., \& Tice, D. M (Eds.). (2011). Psychology of self-regulation: Cognitive, affective, and motivational processes. Taylor \& Francis.

Geurts, S. A. E., \& Sonnentag, S. (2006). Recovery as an explanatory mechanism in the relation between acute stress reactions and chronic health impairment. Scandinavian Journal of Work, Environment \& Health, 32, 482-492.

Gordon, H. J., Demerouti, E., Le Blanc, P. M., Bakker, A. B., Bipp, T., \& Verhagen, M. A. (2018). Individual job redesign: job crafting interventions in healthcare. Journal of Vocational Behavior, 104, 98-114.

Hackman, J. R., \& Oldham, G. R. (1980). Work redesign. Reading, MA: Addison-Wesley.
Hahn, V. C., Binnewies, C., Sonnentag, S., \& Mojza, E. J. (2011). Learning how to recover from job stress: Effects of a recovery training program on recovery, recovery-related self-efficacy, and well-being. Journal of Occupational Health Psychology, 16, 202-216.

Hart, P.M., Wearing, A.J. \& Headey, B. (1995) Police stress and well-being: Integrating personality, coping and daily work experiences. Journal of Occupational and Organizational Psychology, 68, 133-156.

Heuven, E., Bakker, A. B., Schaufeli, W. B., \& Huisman, N. (2006). The role of self-efficacy in performing emotion work. Journal of Vocational Behavior, 69, 222-235.

Higgins, E.T. (2000). Making a good decision: Value from fit. American Psychologist, 55, 1217-1230

Hobfoll, S. E. (2001). The influence of culture, community, and the nested-self in the stress process: advancing conservation of resources theory. Applied Psychology, 50, 337-421.

Hobfoll, S. E. (2002). Social and psychological resources and adaptation. Review of General Psychology, 6, 307-324.

Hobfoll, S. E., Johnson, R. J., Ennis, N., \& Jackson, A. P. (2003). Resource loss, resource gain, and emotional outcomes among inner city women. Journal of Personality and Social Psychology, 84, 632-643.

Hockey, G. R. J. (1993). Cognitive-energetical control mechanisms in the management of work demands and psychological health. In A. Baddely \& L. Weiskrantz (Eds.), Attention: Selection, awareness, and control (pp. 328-345). Oxford: Clarendon Press.

Ito, J. K. \& Brotheridge, C. M. (2001). An examination of the roles of career uncertainty, flexibility, and control in predicting emotional exhaustion. Journal of Vocational Behavior, 59, 406-424.

Jacoby, J. (2002). Stimulus-Organism-Response reconsidered: An evolutionary step in modeling (consumer) behavior. Journal of Consumer Psychology, 12, 51-57. 
Judge, T. A., Bono, J. E., Erez, A., \& Locke, E. A. (2005). Core self-evaluations and job and life satisfaction: The role of self-concordance and goal attainment. Journal of Applied Psychology, 90, 257-268.

Kahn, R. L., \& Byosiere, P. (1992). Stress in organizations. In M. D. Dunnette \& L. M. Hough (Eds.), Handbook of Industrial and Organizational Psychology (Vol. 3; pp. 571-650). Palo Alto, CA: Consulting Psychologists.

Kanten, P. (2014). The antecedents of job crafting: Perceived organizational support, job characteristics and self-efficacy. European Journal of Business and Social Sciences, 3(5), 113-128.

Karasek, R. \& Theorell, T. (1990). Healthy work: Stress, productivity and the reconstruction of working life. New York: Basic Books.

Kinnunen, U., Feldt, T., Siltaloppi, M., \& Sonnentag, S. (2011). Job demands-resources model in the context of recovery: Testing recovery experiences as mediators. European Journal of Work and Organizational Psychology, 20(6), 805-832.

Koeske, G. F. (1993). Coping with job stress: Which strategies work best? Journal of Occupational and Organizational Psychology, 66, 319-336.

Latack, J.C. (1986). Coping with job stress: Measures and future directions for scale development. Journal of Applied Psychology, 3, 377-385.

Lazarus, R. L., \& Folkman, S. (1984). Stress, appraisal, and coping. New York: Springer.

Lee, R. T.; Ashforth, B. E. (1996). A meta-analytic examination of the correlates of the three dimensions of job burnout. Journal of Applied Psychology, 81, 123-133.

Leiter, M. E (1993). Burnout as a developmental process: Consideration of models. In W. B. Schaufeli, C. Maslach, \& T. Marek (Eds.), Professional burnout: Recent developments in theory and research.

Leiter, M. P. (1991). Coping patterns as predictors of burnout: The function of control and escapist coping patterns. Journal of Organizational Behaviour, 12, 123-144.
Mackey J.D. \& Perrewe, P.L. (2014). The AAA (appraisals, attributions, adaptation) model of job stress: The critical role of self-regulation. Organizational Psychology Review, 4, 258-278.

Maslach, C., \& Goldberg, J. (1998). Prevention of burnout: new perspectives. Applied Prevent Psychology, 7, 63-74.

Maslach, C., Schaufeli, W.B., \& Leiter, M.P. (2001). Job burnout. Annual Review of Psychology, 52, 397-422.

Meijman, T. F., \& Mulder, G. (1998). Psychological aspects of workload. In P. J. D. Drenth \& H. Thierry (Eds.), Handbook of work and organizational psychology (Vol. 2, pp. 5-33). Hove: Psychology Press.

Moreno-Jiménez, B., Rodríguez-Muñoz, A., Sanz-Vergel, A. I., \& Garrosa, E. (2012). Elucidating the role of recovery experiences in the job demands-resources model. The Spanish journal of psychology, 15(2), 659-669.

Muraven, M., \& Baumeister, R. F. (2000). Self- regulation and depletion of limited resources: Does self-control resemble a muscle? Psychological Bulletin, 126, 247-259.

Niessen, C., Weseler, D., \& Kostova, P. (2016). When and why do individuals craft their jobs? The role of individual motivation and work characteristics for job crafting. Human Relations, 69(6), 1287-1313.

O'Shea, D., Buckley, F., \& Halbesleben, J. (2017). Self-regulation in entrepreneurs: Integrating action, cognition, motivation, and emotions. $\mathrm{Or}$ ganizational Psychology Review, 7(3), 250-278.

Ohly, S., Sonnentag, S., Niessen, C., \& Zapf, D. (2010). Diary studies in organizational research: An introduction and some practical recommendations. Journal of Personnel Psychology, 9, 79-93.

Op den Kamp, E., Tims, M., Bakker, A. B., \& Demerouti, E. (in press). Proactive Vitality Management in the Work Context: Development and Validation of a New Instrument. European Journal of Work and Organizational Psychology, 
Peterson, U., Bergström, G., Samuelsson, M., Åsberg, M., \& Nygren, Å. (2008). Reflecting peer-support groups in the prevention of stress and burnout: Randomized controlled trial. Journal of Advanced Nursing, 63, 506-516.

Petrou, P., Demerouti, E., \& Schaufeli, W.B. (2013). Employee job crafting in changing environments: Longitudinal relationships with antecedents and outcomes. Manuscript submitted for publication.

Petrou, P., Demerouti, E., Peeters, M.C.W., Schaufeli, W. B., \& Hetland, J. (2012). Crafting a job on a daily basis: Contextual correlates and the link to work engagement. Journal of Organizational Behavior, 33, 1120-1141.

Podsakoff, N. P., LePine, J. A., \& LePine, M. A. (2007). Differential challenge stressor-hindrance stressor relationships with job attitudes, turnover intentions, turnover and withdrawal behavior: A meta-analysis. Journal of Applied Psychology, $92,438-454$

Rijk, A.E. de, Blanc, P.M. Le, Schaufeli, W.B., \& Jonge, J. de (1998). Active coping and need for control as moderators of the Job Demand-Control Model: effects on burnout. Journal of Occupational and Organizational Psychology, 71, 1-18.

Roger, D., Jarvis, G. \& Najarian, B. (1993). Detachment and coping: The construction and validation of a new scale for measuring coping strategies. Personality and Individual Differences, 15, 619-626.

Roth, S., \& Cohen, L. J. (1986). Approach, avoidance, and coping with stress. American Psychologist, 41, 813-819.

Salanova, M., \& Schaufeli, W.B. (2008). A cross-national study of work engagement as a mediator between job resources and proactive behaviour. International Journal of Human Resource Management, 19, 116-131.

Schaubroek, J. \& Merritt, D. E. (1997). Divergent effects of job control on coping with work stressors: The key role of self-efficacy. Academy of Management Journal, 40, 738-754.
Schaufeli, W. B., \& Taris, T. W. (2014). A critical review of the Job Demands-Resources Model: Implications for improving work and health. In G. Bauer \& O. Hämmig (Eds.), Bridging occupational, organizational and public health (pp. 43-68). Dordrecht: Springer.

Schmidt, K. H., Neubach, B., \& Heuer, H. (2007). Self-control demands, cognitive control deficits, and burnout. Work \& Stress, 21(2), 142-154.

Searle, B. J., \& Lee, L. (2015). Proactive coping as a personal resource in the expanded job demands-resources model. International Journal of Stress Management, 22(1), 46.

Siegrist, J. (1996). Adverse health effects of high effort-low reward conditions. Journal of Occupational Health Psychology, 1, 27-41.

Siltaloppi, M., Kinnunen, U., \& Feldt, T. (2009). Recovery experiences as moderators between psychosocial work characteristics and occupational well-being. Work \& Stress, 23(4), 330-348.

Siu, O. L., Spector, P. E., Cooper, C. L., Lu, L., \& $\mathrm{Yu}, \mathrm{S}$. (2002). Managerial stress in greater China: The direct and moderator effects of coping strategies and work locus of control. Applied psychology, 51(4), 608-632.

Sonnentag, S., \& Fritz, C. (2007). The recovery experience questionnaire: Development and validation of a measure for assessing recuperation and unwinding from work. Journal of Occupational Health Psychology, 12, 204-221.

Sonnentag, S., \& Natter, E. (2004). Flight attendants' daily recovery from work: Is there no place like home? International Journal of Stress Management, 11, 366-391.

Sonnentag, S., Binnewies, C., \& Mojza, A.J. (2008). Did you have a nice evening?: A day-level study on recovery experiences, sleep, and affect. Journal of Applied Psychology, 93, 674-684.

Sonnentag, S., Kuttler, I., \& Fritz, C. (2010). Job stressors, emotional exhaustion, and need for recovery: A multi-source study on the benefits of psychological detachment. Journal of Vocational Behavior, 76, 355-365. 
Tangney, J. P., Baumeister, R. F., \& Boone, A. L. (2004). High self-control predicts good adjustment, less pathology, better grades, and interpersonal success. Journal of Personality, 72, 271-322.

Thornton, P. I. (1992). The relation of coping, appraisal and burnout in mental health workers. The Journal of Psychology, 126, 261-271.

Tims, M., Bakker, A. B., \& Derks, D. (2012). Development and validation of the job crafting scale. Journal of Vocational Behavior, 80, 173-186.

Tims, M., Bakker, A.B., \& Derks, D. (2013). The impact of job crafting on job demands, job resources, and well-being. Journal of Occupational Health Psychology, 18, 230-240.

Van den Heuvel, M., Demerouti, E., \& Peeters, M. C. W. (2015). The job crafting intervention: Effects on job resources, self-efficacy, and affective well-being. Journal of Occupational and Organizational Psychology, 88, 511-532.

Van Woerkom, M., Oerlemans, W., \& Bakker, A. B. (2016). Strengths use and work engagement: A weekly diary study. European Journal of Work and Organizational Psychology, 25, 384-397.
Wrzesniewski, A., \& Dutton, J.E. (2001). Crafting a job: Revisioning employees as active crafters of their work. Academy of Management Review, 26, 179-201.

Xanthopoulou, D., Bakker, A. B., Demerouti, E., \& Schaufeli, W. B. (2009). Reciprocal relationships between job resources, personal resources, and work engagement. Journal of Vocational Behavior, 74, 235-244.

Xanthopoulou, D., Bakker, A. B., Demerouti, E., Schaufeli, W. B. (2007). The role of personal resources in the job demands-resources model. International Journal of Stress Management, 14, 121-141.

Xanthopoulou, D., Bakker, A. B., Heuven, E., Demerouti, E., \& Schaufeli, W. B. (2008). Working in the sky: A diary study on work engagement among flight attendants. Journal of Occupational Health Psychology, 13, 345-356.

Yela, J. R. (1996). Desgaste emocional, estrategias de afrontamiento y trastornos psicofisiológicos en profesionales de la enseñanza. Boletín de Psicología, 50, 37-52. 